\title{
Hubungan Status Gizi dengan Perkembangan Psikomotorik Balita di Wilayah Kerja Puskesmas Lapai Padang Tahun 2014
}

\author{
Hamdini Humaira ${ }^{1}$, Yusri Dianne Jurnalis ${ }^{2}$, Edison $^{3}$
}

\begin{abstract}
Abstrak
Permasalahan gizi di Indonesia adalah masih banyaknya kejadian balita gizi kurang dan gizi buruk. Asupan gizi menentukan pertumbuhan dan perkembangan. Ranah perkembangan yang paling sering dinilai di layanan primer adalah perkembangan psikomotorik. Tujuan penelitian ini adalah menentukan hubungan status gizi dengan perkembangan psikomotorik balita di wilayah kerja Puskesmas Lapai. Penelitian ini menggunakan rancangan cross sectional study dengan jumlah sampel sebanyak 106 responden yang diambil secara multistage sampling technique. Data dikumpulkan melalui pengukuran antropometri tinggi dan berat badan serta penilaian KPSP (kuesioner pra skrining perkembangan). Analisis data dilakukan dengan uji Fisher. Hasil penelitian mendapatkan balita dengan perkembangan psikomotorik sesuai lebih tinggi pada status gizi normal $(87,6 \%)$ dibandingkan status gizi tidak normal $(52,9 \%)$. Analisis hubungan antar dua variabel didapatkan nilai $p=0,002$. Secara statistik terdapat hubungan bermakna antara status gizi dengan perkembangan psikomotorik balita. Diperlukan perhatian lebih terutama dari orang tua untuk menjaga kebutuhan gizi balita dan untuk tenaga kesehatan agar meningkatkan pelayanan kesehatan gizi.
\end{abstract}

Kata kunci: status gizi, perkembangan psikomotorik

\begin{abstract}
Nutritional problems in Indonesia is underweight and severely underweight cases in toddlers. The most frequent developmental domain which is assessed in primary health care is psychomotor development. The objective of this study was to determine the relationship between the nutritional status and psychomotor development of toddlers in Lapai Health Center area. This study used a cross sectional study on 106 respondents by multistage sampling technique. Data were collected through anthropometric measurements of height and weight and (DPSQ) development pre-screening questionnaire. Data were tested by Fisher's exact test. The result is toddlers with appropriate psychomotor development were higher in normal nutritional status (87.6\%) compared to abnormal nutritional status (52.9\%). Both variables were $p=0,002$. There is a significant relationship between the nutritional status and psychomotor development. More attention especially from parents to keep the nutritional needs of toddlers and health professionals improve the nutritional health services.
\end{abstract}

Keywords: nutritional status, psychomotor development

Affiliasi penulis: 1. Pendidikan Dokter FK UNAND (Fakultas Kedokteran Universitas Andalas Padang, 2. Bagian IImu Kesehatan Anak FK UNAND, 3. Bagian IImu Kesehatan Masyarakat FK UNAND Korespondensi: Hamdini Humaira, Email:

dhien.humaira@gmail.com, Telp: 08228467787

\section{PENDAHULUAN}

Permasalahan gizi di Indonesia pada balita seperti Kurang Vitamin A (KVA), anemia zat besi dan kekurangan yodium sudah dapat dikendalikan karena proporsi kejadian sudah di bawah batas masalah kesehatan masyarakat. Permasalahan terdapat pada masih banyak balita dengan gizi kurang dan gizi buruk. Laporan Riskesdas 2010, di Indonesia terdapat 4,9\% prevalensi balita dengan status gizi buruk; $17,9 \%$ balita status gizi kurang; $5,8 \%$ balita status gizi lebih. Data Riskesdas juga menyebutkan untuk Provinsi Sumatera Barat terdapat balita dengan status gizi buruk sebesar 2,8 \%; status gizi kurang 14,4\%; status 
gizi lebih 1,6\%. Kasus di Kota Padang ditemukan $9,59 \%$ balita gizi kurang dan $3,16 \%$ balita gizi buruk. ${ }^{1-3}$

Gizi buruk dapat terjadi pada semua kelompok umur, tetapi yang perlu lebih diperhatikan adalah kelompok bayi dan balita. Hal ini dikarenakan pada masa lima tahun pertama kehidupan merupakan masa keemasan (golden period) atau masa kritis (critical period) dimana otak balita lebih plastis sehingga mempunyai sisi positif dan sisi negatif. Sisi positif otak sebagai saraf pusat lebih terbuka untuk proses pembelajaran yang berfungsi untuk perkembangan anak. Sisi negative otak lebih peka terhadap lingkungan utama yang tidak mendukung seperti kurang stimulasi, tidak mendapat pelayanan kesehatan yang memadai dan asupan gizi yang tidak adekuat. Jika terjadi gangguan pada masa ini maka tidak akan dapat dicukupi pada masa berikutnya dan berpengaruh negatif pada kualitas perkembangan generasi penerus. ${ }^{2,4}$

Asupan gizi yang adekuat tidak hanya menentukan pertumbuhan tetapi juga perkembangan karena pertumbuhan dan perkembangan yang baik terjadi secara paralel. Perkembangan (development) penting untuk kasus anak karena perkembangan mencerminkan kematangan persarafan, seperti otak. Selain faktor asupan gizi, ada faktor lain yang mempengaruhi perkembangan balita, yaitu genetik, hubungan dengan manusia (keluarga dan teman), media, masyarakat (budaya), perawatan saat sakit dan kecelakaan fisik. ${ }^{5,6}$

Perkembangan terdiri atas perkembangan psikomotorik, afektif dan kognitif yang saling menunjang satu sama lain. Ranah perkembangan pada balita yang paling sering dinilai di layanan primer (puskesmas atau posyandu) adalah perkembangan psikomotorik yang terdiri atas perkembangan motorik halus, motorik kasar, bahasa-bicara, kemandirian dan sosial anak. Pada beberapa sumber seperti Depkes RI, perkembangan psikomotorik sudah lazim disebut sebagai perkembangan saja yang dinilai dengan KPSP (Kuesioner Pra Skrining Perkembangan). ${ }^{4,5}$

Penelitian sebelumnya oleh Zulaikhah (2010), membuktikan bahwa terdapat hubungan status gizi dengan perkembangan balita, dengan hasil uji statistik menunjukkan signifikansi 0,039 $(p<0,05)$. Penelitian ini mendapatkan persentase anak yang memiliki perkembangan yang normal lebih tinggi pada anak dengan status gizi normal $(82,2 \%)$ daripada anak dengan status gizi kurus $(7,1 \%)^{7}$

Wilayah kerja Puskesmas Lapai dan Puskesmas Belimbing merupakan wilayah dengan persentase tertinggi untuk penjumlahan data gizi buruk dan gizi kurang balita di Kota Padang. Puskesmas Belimbing di urutan pertama dengan jumlah data gizi buruk dan gizi kurang sebesar 20\%; Puskesmas Lapai di urutan kedua sebesar 15,83\%. Jika dibandingkan dengan Puskesmas Lapai, persentase gizi buruk di Puskesmas Belimbing jauh lebih rendah (1,54\%) dibandingkan Puskesmas Lapai yang termasuk urutan tertinggi gizi buruk (5\%) di Kota Padang. Sementara untuk kasus perkembangan tidak didapatkan data yang lengkap di Puskesmas Lapai karena belum didapatkan sumber data yang resmi. Kurangnya data tentang perkembangan dan belum pernah dilakukan penelitian mengenai hubungan status gizi dengan perkembangan psikomotorik balita di Padang inilah yang membuat perlu diteliti apakah ada hubungan status gizi dan perkembangan psikomotorik pada balita di wilayah kerja Puskesmas Lapai Padang. ${ }^{3}$

\section{METODE}

Penelitian ini dilakukan di enam posyandu wilayah kerja Puskesmas Lapai Padang dari Mei sampai Juni 2014. Sampel pada penelitian ini adalah balita yang tinggal menetap di Lapai dan memenuhi kriteria inklusi dan eksklusi. Kriteria inklusi adalah orang tua anak bersedia menjadi responden; pengasuh balita adalah orang tua yang tidak bekerja (ibu rumah tangga); balita jika sakit dibawa berobat ke petugas medis (dokter dan bidan) seperti di puskesmas, rumah sakit atau klinik. Adapun kriteria eksklusi pada penelitian ini adalah balita tidak berada di posyandu atau di rumah saat kunjungan; balita memiliki cacat bawaan, riwayat asfiksia, riwayat BBLR, premature; balita memiliki riwayat trauma fisik (kelemahan atau kehilangan anggota fisik) atau trauma kepala (molase atau fraktur).

Penelitian ini menggunakan desain crosssectional study dengan mewawancarai dan mengukur berat dan tinggi badan (BB/TB) 106 orang responden dengan alat bantu KPSP (Kuesioner Pra Skrining Perkembangan), timbangan dacin atau digital, 
mikrotois atau length board.Responden dipilih secara acak dengan teknik multistage random sampling. Data dianalisis secara univariat dan bivariat menggunakan uji Fisher pada derajat kepercayaan $\mathrm{p}<0,05$. Variabel dependen adalah perkembangan psikomotorik, sedangkan variabel independen adalah status gizi.

\section{HASIL}

Tabel 1. Distribusi frekuensi karakteristik responden

\begin{tabular}{lcc}
\hline \multicolumn{1}{c}{ Karakteristik Responden } & $\mathbf{f}$ & $\%$ \\
\hline Usia & & \\
$\quad$ 0-3 tahun & 74 & 69,8 \\
$\quad>3-5$ tahun & 32 & 30,2 \\
Jenis Kelamin & & \\
Laki-laki & 48 & 45,3 \\
Perempuan & 58 & 54,7 \\
Cara Persalinan & & \\
Normal & 77 & 72,6 \\
Sectio Caesarea & 25 & 23,6 \\
Ekstraksi vakum/cunam & 4 & 3,8 \\
\hline \multicolumn{1}{c}{ Total } & 106 & 100 \\
\hline
\end{tabular}

Berdasarkan Tabel 1 dapat dilihat bahwa dari 106 balita diketahui persentase usia terbanyak adalah kelompok usia 0-3 tahun (69,8\%). Tabel 1 juga didapatkan responden dengan jenis kelamin perempuan (58\%) lebih banyak daripada laki-laki. Riwayat kelahiran responden melalui persalinan normal adalah cara persalinan terbanyak (72,6\%), kemudian sectio caesarea dan yang paling sedikit adalah lewat ekstraksi vakum/cunam.

Status gizi responden dibedakan menjadi 4 kategori, yaitu status gizi sangat kurus, kurus, gemuk dan normal. Hasil distribusi frekuensi status gizi responden dapat dilihat dalam tabel 2 berikut.

Tabel 2. Distribusi frekuensi status gizi responden

\begin{tabular}{|c|c|c|}
\hline Status Gizi & $f$ & $\%$ \\
\hline Normal & 89 & 84 \\
\hline Gemuk & 4 & 3,8 \\
\hline Kurus & 12 & 11,3 \\
\hline Sangat kurus & 1 & 0,9 \\
\hline Total & 106 & 100 \\
\hline
\end{tabular}

Pada Tabel 2 dapat dilihat balita yang memiliki status gizi normal merupakan jumlah status gizi terbanyak (84\%). Penilaian perkembangan psikomotorik dibedakan menjadi 3 kategori, yaitu sesuai, meragukan dan penyimpangan. Data hasil penilaian perkembangan psikomotorik dapat dilihat pada tabel berikut.

Tabel 3. Distribusi frekuensi menurut perkembangan psikomotorik responden

\begin{tabular}{lcc}
\hline \multicolumn{1}{c}{ Perkembangan } & $\mathbf{f}$ & $\%$ \\
\hline Sesuai & 87 & 82,1 \\
Meragukan & 19 & 17,9 \\
Penyimpangan & 0 & 0 \\
\hline \multicolumn{1}{c}{ Total } & 106 & 100 \\
\hline
\end{tabular}

Berdasarkan Tabel 3 di atas dapat dilihat penilaian perkembangan psikomotorik dengan hasil sesuai merupakan perkembangan psikomotorik terbanyak $(82,1 \%)$ di antara 106 responden.

Perkembangan psikomotorik balita terdiri dari aspek motorik kasar, motorik halus, bicara dan bahasa, dan sosial dan kemandirian. Tabel 4 berikut adalah jumlah kejadian gangguan aspek perkembangan psikomotorik pada balita.

Tabel 4. Distribusi frekuensi gangguan aspek perkembangan psikomotorik responden

\begin{tabular}{lcc}
\hline $\begin{array}{l}\text { Gangguan aspek perkembangan } \\
\text { psikomotorik }\end{array}$ & $\mathbf{f}$ & $\%$ \\
\hline Motorik kasar & 17 & 33,3 \\
Motorik halus & 16 & 31,4 \\
Bicara dan bahasa & 8 & 15,7 \\
Sosialisasi dan kemandirian & 10 & 19,6 \\
\hline \multicolumn{1}{c}{ Total } & 51 & 100 \\
\hline
\end{tabular}

Pada Tabel 4 dapat dilihat bahwa dari 51 kasus, gangguan aspek perkembangan psikomotorik yang terbanyak adalah gangguan motorik kasar sebanyak 17 kasus (33,3\%).

Untuk mengetahui hubungan status gizi dengan perkembangan psikomotorik, kategori status gizi dibedakan menjadi normal dan tidak normal (sangat kurus+kurus+gemuk). Kategori perkembangan psikomotorik dibagi menjadi: sesuai dan meragukan (meragukan+penyimpangan). Hasil analisis bivariat dapat dilihat pada Tabel 5 berikut. 
Tabel 5. Hubungan status gizi dengan perkembangan psikomotorik responden

\begin{tabular}{|c|c|c|c|c|c|c|}
\hline \multirow[t]{3}{*}{$\begin{array}{l}\text { Status } \\
\text { Gizi }\end{array}$} & \multicolumn{4}{|c|}{$\begin{array}{c}\text { Perkembangan } \\
\text { Psikomotorik }\end{array}$} & \multirow{2}{*}{\multicolumn{2}{|c|}{$\mathbf{p}$}} \\
\hline & \multicolumn{2}{|c|}{ Sesuai } & \multicolumn{2}{|c|}{ Meragukan } & & \\
\hline & $f$ & $\%$ & $f$ & $\%$ & $f$ & \\
\hline Normal & 78 & 87,6 & 11 & 12,4 & 89 & 0,002 \\
\hline Tidak & 9 & 52,9 & 8 & 47,1 & 17 & \\
\hline Total & 87 & 82,1 & 19 & 17,9 & 106 & \\
\hline
\end{tabular}

Berdasarkan Tabel 5 dapat dilihat bahwa persentase responden dengan perkembangan psikomotorik sesuai lebih banyak pada status gizi normal $(87,6 \%)$ daripada status gizi tidak normal (52,9\%). Hasil uji statistik menunjukkan bahwa terdapat hubungan yang signifikan antara status gizi dengan perkembangan psikomotorik balita di posyandu wilayah kerja Puskesmas Lapai karena $p=$ $0,002(p<0,05)$.

\section{PEMBAHASAN}

Berdasarkan karakteristik usia diketahui sebagian besar $(69,8 \%)$ responden berada pada rentang usia 0-3 tahun. Periode tiga tahun pertama pada masa balita merupakan periode emas pertumbuhan fisik, intelektual, mental, dan emosional anak. Pertumbuhan dan perkembangan otak paling cepat 3 tahun pertama sehingga menjadi pengukuran rutin dari pengkajian nutrisi anak sampai umur 3 tahun. 8,9

Pertumbuhan dan perkembangan anak laki-laki dan perempuan berjalan paralel hampir sama sampai akhir dekade pertama kehidupan. Biasanya anak perempuan cenderung memiliki berat badan yang lebih ringan dari pada laki-laki. ${ }^{10,11}$

Balita yang dilahirkan melalui persalinan normal $(72,6 \%)$ adalah jumlah terbanyak dari responden kemudian diikuti sectio caesarea $(23,6 \%)$ dan dengan bantuan ekstraksi vakum/cunam (3,8\%). Anak yang lahir lewat persalinan selain normal dapat memiliki risiko kecenderungan perkembangan yang lebih lambat daripada persalinan normal. Menurut Prawirohardjo (2011), efek atau gangguan pada janin yang lahir tidak dilihat dari proses persalinan, tetapi apakah persalinan mengakibatkan ganggguan pada kepala janin. Molase dan faktur kepala janin karena upaya paksa persalinan juga dapat terjadi pada persalinan spontan dan sectio caesarea. ${ }^{11,12}$

Penilaian status gizi dilakukan secara langsung dengan mengukur antropometri balita dan dinilai berdasarkan berat badan menurut tinggi badan (BB/TB). Hasil penelitian menunjukkan status gizi normal merupakan jumlah terbanyak, yaitu 89 responden (84\%), dilanjutkan oleh gizi kurus sebanyak 12 responden $(11,3 \%)$, status gizi gemuk 4 responden $(3,8 \%)$, status gizi sangat kurus 1 responden $(0,9 \%)$.

Status gizi dapat memberikan informasi tentang kualitas diet karena pertumbuhan seorang anak yang normal tidak mungkin terjadi tanpa asupan yang adekuat. Status gizi normal terjadi karena keseimbangan antara konsumsi, penyerapan zat gizi, dan penggunaan zat gizi yang baik. Keadaan patologis akibat kekurangan atau kelebihan zat gizi untuk periode tertentu dapat berdampak pada status gizi. Status gizi kurus dan sangat kurus terjadi jika kekurangan konsumsi pangan sedangkan status gizi gemuk terjadi jika mengalami kelebihan konsumsi pangan. ${ }^{13,14}$

Hasil penelitian perkembangan psikomotorik menunjukkan mayoritas responden memiliki perkembangan yang normal atau sesuai dengan tahap usia balita. Perkembangan psikomotorik dengan hasil sesuai adalah sebanyak 87 responden $(82,1 \%)$. Perkembangan yang tidak normal seperti perkembangan yang meragukan terdapat sebanyak 19 responden $(17,9 \%)$ sedangkan untuk penyimpangan perkembangan tidak didapatkan di lapangan $(0 \%)$.

Penilaian perkembangan dilakukan dengan KPSP (Kuesioner Pra Skrining Perkembangan) yang terdiri dari 9-10 kuesioner sesuai usia balita. Perkembangan balita yang sesuai umur bila balita dapat melakukan perintah atau pertanyaan kuesioner sebanyak 9-10 poin. Jika hanya memenuhi 7-8 poin perkembangan balita meragukan. Poin $\leq 6$ pada KPSP dinilai perkembangan balita tersebut mengalami penyimpangan perkembangan. Namun, di lapangan peneliti hanya mendapatkan perkembangan yang sesuai dan meragukan. ${ }^{4}$

Apabila ditinjau dari komponen perkembangan psikomotorik yang terganggu maka semua komponen mengalami gangguan, yang terbanyak adalah 
gangguan motorik kasar sebanyak 17 kasus $(33,3 \%)$ diikuti motorik halus 16 kasus $(31,4 \%)$. Hal ini sesuai dengan penelitian Gunawan et al (2011) di Bandung yang juga mendapatkan perkembangan motorik adalah komponen yang mengalami gangguan terbanyak. Penelitian di dua tempat penitipan anak di Piracicaba SP Brazil tahun 2010 mendapatkan 30\% anak mengalami keterlambatan perkembangan motorik kasar dan motorik halus pada subjek berusia 12-17 bulan. $^{15}$

Perkembangan bicara, motorik, dan perilaku jelas dan lebih mudah terdeteksi oleh orang tua atau orang yang merawat anak. Namun terdapat beberapa orang tua yang tidak memiliki pengetahuan tentang perkembangan anak secara normal sehingga keterlambatan perkembangan tetap terjadi. ${ }^{16}$

Persentase responden dengan perkembangan psikomotorik sesuai lebih banyak pada status gizi normal daripada status gizi tidak normal. Pada penelitian ini, hasil uji didapatkan sesuai dengan teori yang menyatakan bahwa salah satu yang mempengaruhi perkembangan psikomotorik adalah status gizi ( $p=0,002$ melalui Fisher's Exact Test).

Pada penelitian didapatkan responden dengan status gizi normal yang memiliki perkembangan sesuai sebanyak 78 responden (87,6\%). Responden status gizi normal dengan perkembangan psikomotorik meragukan berjumlah 11 responden (12,4\%). Responden yang memiliki status gizi tidak normal (sangatkurus, kurus, gemuk) yang mengalami perkembangan psikomotorik sesuai adalah sembilan responden $(52,9 \%)$ sedangkan yang mengalami perkembangan psikomotorik meragukan adalah delapan responden $(47,1 \%)$.

Pematangan fungsi otak tidak semata-mata oleh proses biologis (asupan gizi), tetapi sangat dipengaruhi pula oleh kualitas pengalaman interaksi dengan lingkungan pengasuhan. Responden dengan status gizi normal yang memiliki perkembangan yang sesuai berarti telah diberi asupan gizi dan faktor lain yang baik seperti stimulasi perkembangan dari orang tua. Sebaliknya, anak dengan status gizi normal tetapi perkembangan meragukan mengindikasikan kurang stimulasi dan ketidaktahuan orang tua tentang pentingnya menstimulasi perkembangan anak. ${ }^{17,18}$
Kontraksi otot dapat terjadi bila tersedianya energi. Energi yang diperoleh otot dari persediaan energi yang dimiliki otot atau mobilisasi dari tempat lain. Energi yang dihasilkan tersebut akan digunakan untuk kerja otot, transmisi saraf, kerja enzim, dan fungsi lainnya. ${ }^{19}$

Anak yang masa balitanya kekurangan makanan bergizi biasanya akan mengalami keterlambatan pertumbuhan (kurus). Anak yang kurang gizi akan cenderung menjadi anak yang lemah dan kurang minat terhadap kegiatan di sekelilingnya (gerak motorik). Bila kurang gizi (otot dan zat gizi kurang) anak pun tidak aktif, padahal bergerak aktif berfungsi untuk melatih keterampilan motorik. Anak yang kurang gizi cenderung mudah tersinggung, pemurung, tidak dapat diduga dan sangat gugup (bicara dan bahasa serta sosial dan kemandirian). ${ }^{12,19}$

Pada beberapa responden status gizi kurus (lima orang) atau gemuk (empat orang) yang memiliki perkembangan yang sesuai mengindikasikan kemungkinan faktor selain asupan gizi dapat tercukupi, seperti lingkungan sosial yang mendukung (stimulasi dari orang tua yang adekuat). Orang tua responden rajin mengajak anak bermain bersama, bercakap-cakap, atau anak aktif bermain dengan teman sebayanya. $^{16}$

Banyak faktor lain yang mempengaruhi perkembangan. Faktor tersebut meliputi fase pranatal, natal, dan postnatal. Pada fase prenatal, gizi ibu yang kurang dapat menyebabkan BBLR (berat badan lahir rendah) yaitu berat bayi <2500 g yang memiliki risiko gangguan perkembangan pada tahap selanjutnya. ${ }^{5,12}$

Bayi yang prematur (persalinan berlangsung umur 20-37 minggu) masih mempunyai morbiditas yang tinggi (risiko kelainan jangka panjang dan jangka pendek). Kelainan jangka pendek seperti RDS (Respiratory Distress Syndrome) dan risiko asfiksia; kelainan jangka panjang sering berupa kelainan neurologik seperti serebral palsi, retardasi mental, atau prestasi sekolah yang kurang baik. Pada penelitian ini responden diambil yang tidak memiliki riwayat BBLR, prematur dan asfiksia. Balita dengan riwayat kelainan kongenital juga tidak dimasukkan agar tidak menjadi bias karena dapat mempengaruhi perkembangan bayi. ${ }^{13}$ 
Pada Fase natal, bila terjadi molase atau fraktur tengkorak dapat menyebabkan robeknya bagian otak seperti tentorium serebelli yang dapat terjadi baik pada persalinan dengan komplikasi maupun persalinan normal. Pada penelitian ini responden diambil yang tidak memiliki riwayat molase atau fraktur kepala. ${ }^{13}$

Fase postnatal adalah pola asuh orang tua Faktor stimulasi memegang peranan penting dalam tumbuh kembang anak. Anak yang mendapat stimulasi terarah dan teratur akan lebih cepat berkembang dibandingkan dengan anak yang tidak/kurang mendapatkan stimulasi. Ibu yang tidak bekerja atau berstatus ibu rumah tangga dapat lebih memperhatikan perkembangan anaknya. lbu yang tidak bekerja atau berstatus ibu rumah tangga dapat lebih memperhatikan perkembangan anaknya.,20

Cacat fisik (kehilangan anggota tubuh) karena didapat (trauma) atau kelainan kongenital dapat mengganggu perkembangan anak. Pada penelitian ini semua responden yang diambil adalah yang tidak memiliki cacat fisik. ${ }^{6}$

Keterbatasan lain adalah ada beberapa responden balita yang sulit beradaptasi dengan orang yang baru dikenalnya sehingga balita segan untuk mengikuti intruksi. Peneliti biasanya mengatasi dengan mengajak kerjasama keluarga untuk mengajak balita atau menanyakan kepada keluarganya apakah balita telah mencapai tahapan perkembangan tersebut. Kekurangan yang lain adalah peneliti tidak mengambil seluruh posyandu (18 buah posyandu) wilayah kerja puskesmas karena keterbatasan dari penulis sendiri.

Keterbatasan dari segi desain penelitian adalah desain penelitian yang menggunakan cross sectional study, yang paling mudah dilaksanakan dan sangat sederhana tetapi merupakan desain yang paling lemah dalam penelitian survei analitik.

Penelitian ini sejalan dengan penelitian oleh Zulaikhah (2010) di kota Surakarta yang mendapatkan adanya hubungan status gizi dengan perkembangan lewat uji statistik $(p=0,039)$. Penelitian ini mendapatkan persentase anak yang memiliki perkembangan yang normal lebih tinggi pada anak dengan status gizi normal $(82,2 \%)$ daripada anak dengan status gizi kurus $(7,1 \%)^{7}$
Penelitian serupa dilakukan oleh Dewi (2011) di Kabupaten Jepara, juga mendapatkan hasil yang menyatakan bahwa terdapat hubungan status gizi dengan perkembangan balita dengan $p=0,001$. Penelitian ini mendapatkan persentase anak yang memiliki perkembangan yang normal lebih tinggi pada anak dengan status gizi normal $(71 \%)$ daripada anak dengan status gizi kurus $(0 \%) .{ }^{18}$

\section{KESIMPULAN}

Terdapat hubungan yang bermakna antara status gizi dengan perkembangan psikomotorik balita di wilayah kerja Puskesmas Lapai.

\section{SARAN}

Peran orang tua sangat diperlukan untuk memperhatikan, menambah wawasan tentang kebutuhan gizi dan perkembangan balita agar kebutuhan gizi balita dapat tercukupi dan perkembangan dapat sesuai dengan usia. Balita dibawa ke posyandu untuk pemantauan status gizi setiap bulan agar ditatalaksana bila terdapat masalah gizi dan gangguan perkembangan.

Peran tenaga kesehatan diharapkan dapat meningkatkan pelayanan mengenai status gizi anak dan upaya deteksi dinipenyimpangan perkembangan balita secara rutin, memberikan penyuluhan dan pengobatan untuk mengatasi masalah gizi dan atau perkembangan psikomotorik balita yang terlambat, terutama di bidang perkembangan yang sering bermasalah seperti pada penelitian ini adalah motorik kasar.

Perlu penelitian lebih lanjut mengenai hubungan status gizi dengan perkembangan psikomotorik pada balita pada wilayah penelitian berbeda, variabel lain yang belum dimasukkan dalam penelitian ini, dan desain penelitian yang lebih baik.

\section{DAFTAR RUJUKAN}

1. Kemenkes. Penuhi kebutuhan gizi pada 1000 hari pertama kehidupan. Rilis Berita [serial online] 2012 (diunduh 3 januari 2014). Tersedia dari: URL: HYPERLINK http://www.depkes.go.id/index.php? $\mathrm{vw}=2 \& \mathrm{id}=2014$

2. Kemenkes. Anak dengan gizi baik menjadi aset dan investasi bangsa di masa depan. Rilis Berita 
[serial online] 2010 (diunduh 2 Januari 2014). Tersedia dari: URL: HYPERLINK http://www. depkes.go.id/index.php?vw=2\&id=1346

3. Dinas Kesehatan Kota Padang. Tabel profil kesehatan kota Padang. Profil Kesehatan [serial online] 2013 (diunduh 16 Desember 2013). Tersedia dari: URL: HYPERLINK http://dinkeskota padang1.wordpress.com/profil-kesehatan/profiltahun-12-edisi-13/tabel-profil-12/.

4. Depkes RI. Pedoman pelaksanaan stimulasi, deteksi dan intervensi dini tumbuh kembang anak di tingkat pelayanan kesehatan dasar. Jakarta: Depkes; 2005.

5. Soetjiningsih. Tumbuh kembang anak. Jakarta: EGC; 2003.

6. Santrock JW. Perkembangan anak. Edisi ke-1. Jakarta: Erlangga; 2007

7. Zulaikhah S. Hubungan status gizi dengan perkembangan anak usia 2 sampai 3 tahun di wilayah kerja Puskesmas Gambir kota Surakarta (tulis ilmiah). Surakarta: Universitas Sebelas Maret; 2010.

8. Kemenkes. Pentingnya pemantauan kesehatan pada masa periode emas balita. Rilis Berita [serial online] 2011 (diunduh 2 Januari 2014). Tersedia dari: URL: HYPERLINK

http://www.depkes.go.id/index.php?vw=2\&id=1597.

9. Sjarif DR, Lestari ED, Mexitalia M, Nasar SS, editor (penyunting). Buku ajar nutrisi pediatrik dan penyakit metabolik. Jakata: IDAI; 2011.

10. Guyton AC, Hall JE. Buku Ajar Fisiologi Kedokteran. Edisi ke-11. Jakarta: EGC; 2008.
11. Hurlock EB. Perkembangan anak. Edisi ke-1. Jakarta: Erlangga; 2004.

12. Prawirohardjo S. Ilmu kebidanan. Jakarta: PT Bina Pustaka; 2011. hlm. 569-573.

13. Geissler CA, Powers HJ. Human nutrition. China: Elsevier Churchill Livingstone; 2005.

14. Supariasa IDN, Bakri B, Fajar I. Penilaian status gizi. Jakarta: EGC; 2002.

15. Gunawan G, Fadlyana E, Rusmil K. Hubungan status gizi dan perkembangan anak usia 1-2 tahun. Sari Pediatri. 2011;13(2):143.

16. Tjandrajani A, Dewanti A, Burhany AA, Widjaja JA. Keluhan utama pada keterlambatan perkembangan umum di klinik khusus tumbuh kembang RSAB Harapan Kita. Sari Pediatri. 2012; 13(6):373-7.

17. Soedjatmiko. Pentingnya stimulasi dini untuk merangsang perkembangan bayi dan balita terutama pada bayi risiko tinggi. Sari Pediatri. 2006;8(3):164-173.

18. Dewi RS. Hubungan status gizi dengan perkembangan balita di tahunan kabupaten Jepara (karya tulis ilmiah). Surakarta: Universitas Sebelas Maret; 2011.

19. Afriwardi. Ilmu kedokteran olahraga. Jakarta: EGC; 2010.

20. Arimurti IS. Perbedaan perkembangan bayi pada ibu bekerja dan tidak bekerja di bidan praktek swasta Satimah Sawangan Depok (skripsi). Surabaya: Universitas Airlangga; 2010. 